\title{
La trepidante carrera de sir Benjamin Wright. Comerciante, factor y asentista de Felipe $I V^{*}$
}

\author{
Ángel Alloza Aparicio \\ CSIC
}

\section{Juan Carlos Zofío Llorente}

Grupo Taller de Historia Social

RESUMEN: Este artículo reconstruye la trayectoria de un comerciante inglés instalado en Madrid a principios de la década de 1630, que a mediados de la siguiente se había convertido en banquero de Felipe IV. Interrumpida de súbito su trepidante carrera debido a la suspensión de pagos de octubre de 1647, Benjamin Wright aún dejó constancia de una gran tenacidad hasta el final de sus días. La reconstrucción de sus negocios se ha efectuado a partir de fuentes primarias provenientes en gran parte del Archivo Histórico de Protocolos Notariales de Madrid, así como del Archivo General de Simancas. Entre otras cuestiones de relevancia, dichas fuentes han permitido observar por primera vez con cierta nitidez en el complejo mundo de las finanzas de la monarquía hispánica, las diferencias existentes entre lo que se asentó y lo que finalmente se ejecutó, así como las registradas entre el dinero que el inglés colocó en su destino final y el que logró recuperar sobre los pagos que le libró la real hacienda. Microhistoria e Historia Económica y Social se ensamblan en este trabajo para producir un ejemplo paradigmático de movilidad social ascendente en la España del siglo XVII.

\section{Palabras ClaVE: Comercio; finanzas; España; siglo XVII; Benjamin Wright.}

* Citas de archivos: AHPNM: Archivo Histórico de Protocolos Notariales de Madrid; ARCHV: Archivo de la Real Chancillería de Valladolid; AGS: Archivo General de Simancas; BNE: Biblioteca Nacional de España; AHN: Archivo Histórico Nacional. Este trabajo se inscribe en los proyectos I+D (HAR2009-11939) e Intramural (CSIC 200910/023). Agradecemos los comentarios de Alberto Marcos y Máximo Diago. 
The Frenetic Career of Sir Benjamin Wright. Merchant, factor and asentista of Philip IV of Spain

ABSTRACT: This paper draws the career of an English merchant settled in Madrid at the beginning of 1630's who, at the middle of the following decade, had become banker of Philip IV. Suddenly interrupted his career due to the bankrupt of October 1647, Benjamin Wright proved to be a tenacious man during the rest his life in Spain. The reconstruction of his businesses has been made on the basis of primary sources from different archives (notably Archivo Histórico de Protocolos Notariales de Madrid and Archivo General de Simancas). These sources have allowed us to appreciate for first time with a certain degree of clarity into the complex world of the Spanish royal finances, the existing differences between the amounts of money Benjamin agreed to lend the king, and the money that was actually transferred to its final destination. Also the differences between the money Benjamin lent and the amounts he actually recovered. Along the paper, Micro-history and Economic and Social History often meet, and this produces a paradigmatic example of ascending social mobility in Seventeenth Century Spain.

KEY WORDS: Trade; finances; Spain; Seventeenth Century; Benjamin Wright.

\section{INTRODUCCIÓN}

Benjamin Wright apareció en Madrid a comienzos de 1631. Con anterioridad introducía en la capital géneros textiles ingleses de la mano del mercader de lonja francés Daniel Sabola ${ }^{1}$. En diciembre se declaraba «estante» en la corte $^{2}$, desde donde comenzaba a extender sus negocios por el interior de Castilla, al tiempo que negociaba con letras de cambio y otros productos financieros. También compraba enormes cantidades de lana para conducirlas a Londres y Provincias Unidas vía San Sebastián y Bilbao.

A comienzos de 1635 ya contaba con propiedades inmobiliarias en Madrid, era cabeza de una red comercial a escala internacional y, en pocos meses más, como consecuencia de la ruptura de España con Francia, titular de una gran cantidad de licencias especiales para introducir mercancías francesas de contrabando. Era la suya una carrera fulgurante: en 1639, fruto esta vez de las urgencias del conde duque de Olivares para conducir soldados a Flandes, se convirtió en factor de Felipe IV, con cuya comisión organizó el transporte de miles de infantes y soldados a Países Bajos e Italia.

En 1643 fue reclutado por el consejo de hacienda como asentista, y entre esa fecha y 1646 firmó cinco asientos para colocar algo más de 900.000 escu-

1 AHPNM, Protocolos 3.923 y 4.667, fols. 1.412-1.415.

2 AHPNM, Protocolo 4.667, fols. 1.502-1.503. 
dos en Amberes y Milán. No ejecutó la totalidad de lo asentado, aún así el decreto de suspensión de pagos de primero de octubre de 1647 quebró la ascendente de este «listo, emprendedor y audaz financiero», por utilizar algunos de los calificativos que le brindaron Harland Taylor y más tarde Felipe Ruiz Martín ${ }^{3}$.

La capacidad, habilidad y audacia que mostró Sir Benjamin Ruit ${ }^{4}$ en sus negocios se vio favorecida por una coyuntura internacional muy favorable para los mercaderes ingleses asentados en los puertos españoles a partir de 1630 porque, a pesar de la crisis comercial británica registrada desde comienzos de la década anterior ${ }^{5}$, al prolongado conflicto de la monarquía hispánica con las Provincias Unidas se le unió el rompimiento con Francia de 1635, lo que obligó a Madrid a variar oportunamente las rutas para el transporte de dinero a Flandes, del Mediterráneo al canal de la Mancha, muy especialmente tras la caída de Breisach en 1638, así como a utilizar embarcaciones inglesas (neutrales) para este fin. El comercio inglés también garantizaría los tráficos de septentrión con la península Ibérica ${ }^{6}$.

Harland Taylor afirmó hace décadas que el auge de la colonia inglesa en España, representada con los Pawley, Lant, Crocker, Inkleton o Ruit, primero con las licencias especiales, luego con los barcos para cargar soldados y finalmente con las factorías y préstamos de dinero, se debió menos a su competencia profesional, que a las necesidades financieras de la corona producidas tras la huida de los Balbi, Centurione, Serra o Spinola; y añadió que muchos de estos factores improvisados fueron escasamente más que patentees o arrendatarios de rentas, cuyo retorno a la oscuridad no se iba a retrasar más allá de la llegada de la paz o de la siguiente bancarrota, sin perjuicio de que algunos de ellos hicieran pequeñas fortunas gracias al contrabando de materiales de guerra, el abastecimiento de grano para el ejército en Cataluña, o la realización de contratos para abastecer barcos armados destinados a la protección de la Carrera de Indias ${ }^{7}$.

Lo cierto es que Benjamin Ruit supo aprovechar la coyuntura favorable y las oportunidades que se le brindaron, pero su competencia profesional queda fuera de toda duda, como se comprobará en las páginas que siguen. Así, al contrario de lo que afirmó Taylor en su día, la trayectoria de Ruit como hombre de negocios es realmente admirable, y su estudio constituye un gran contribución no solo al conocimiento del comercio inglés en España a mediados

3 TAYLOR, 25/2 (1972): 236-260, 253; RUIZ MARTÍN, 1990: 94.

4 En la documentación española aparece como Ruit.

5 SUPPLE, 1959.

6 La mejoría del tráfico inglés se debió al «nuevo comercio español», muy especialmente desde la rotura de la tregua con los holandeses en 1621. FISHER, 1969: 64-77.

7 TAYLOR, 25/2 (1972): 236-260, 253. 
del siglo XVII, del que ya disponemos de interesantes aportaciones ${ }^{8}$, sino también a la historia económico-financiera en las décadas centrales del Seiscientos, en particular en lo que respecta a las finanzas de la monarquía hispánica y el crédito internacional, sobre las cuales también disponemos de notables estudios ${ }^{9}$, y en menor medida a la actividad bancaria y el crédito privado al pequeño comercio, un mundo aún por descubriri ${ }^{10}$.

\section{ESTABLECIMIENTO EN MADRID}

Benjamin era un gentleman de buena familia, originario de Essex, hijo de Robert Wright (Suffolk), y hermano de Nathan y Ezekiel ${ }^{11}$. En The History of the Rebellion and Civil Wars in England, Clarendon confirmó que Benjamin era el pequeño de la familia Wright y que creció como mercader en Madrid, con grandes negocios y reputación, y que allí se hizo español no solo en lo relativo al lenguaje, sino también en la generosa parte de su naturaleza y costumbres. Le gustaban los caballos y el uso de las armas ${ }^{12}$.

En marzo de 1632 vivía junto a San Luis ${ }^{13}$, y trabajaba con Jofre Inkleton, un compatriota que después se establecería en San Sebastián y actuaría como correspondiente suyo en aquel puerto ${ }^{14}$. Su actividad predominante por aquellas fechas era la venta de bayetas, sempiternas, sargas y anascotes a mercaderes de ropería y roperos de Toledo, Alcalá de Henares y Madrid. También negociaba con letras de cambio: en Madrid admitía letras giradas desde Sevilla por Richard Suit, uno de los pocos ingleses que logró naturalizarse castellano en la época de Olivares ${ }^{15}$.

Poco a poco fue extendiendo su red de agentes por toda la península Ibérica, otorgando poderes a numerosos tratantes que se encargaban de cobrar las deudas que los comerciantes menudos de Salamanca, Ciudad Rodrigo y otras poblaciones castellanas habían contraído con Ruit. También autorizó a Marmaduke Rawden, conocido mercader inglés radicado en Tenerife, para cobrar deudas que algunos cosecheros de vino de aquella isla tenían contraídas con

8 STECKLEY, 1984. MARTÍNEZ y GAUCI, 2008. GUERRA CABRERA, 1994. DIAGO, 49 (MADRID, 2009): 397-445.

9 DOMÍNGUEZ ORTIZ, 1960. BOYAJIAN, 1983. GELABERT, 1997. ÁLVAREZ NOGAL, 1997. RUIZ MARTIN, 1990. SANZ AYÁN, 2004.

10 GARCÍA GUERRA y DE LUCA, 2009.

11 The Memoirs of Ann Lady Fanshawe, wife of the right honorable Sir Richard Fanshawe, 1600-1672. London y New York, John Lane, 1907: 503.

12 CLARENDON, 1892, book XII: 85-87.

13 AHPNM, Protocolo 3.924, fol. 103v.

14 AHPNM, Protocolo 2.504, fols. 342-343.

15 AHPNM, Protocolos 4.670 y 4.671. 
Benjamin ${ }^{16}$. Inició el año de 1633 ampliando su oferta, esta vez a la venta de pescado ${ }^{17}$, y alargando los tentáculos de su negocio de letras de cambio: entre otros, negoció con Francisco de Manzano, tesorero de la junta del almirantazgo, admitiendo letras sobre los valores de los géneros de contrabando aprehendidos por los veedores de dicha institución.

Durante el siguiente año Ruit desarrolló una intensa actividad en el ámbito comercial y financiero. El Archivo Histórico de Protocolos de Madrid conserva numerosos registros de sus operaciones. En concreto, en 1634 se registran 16 escrituras de obligación suscritas por múltiples mercaderes con Benjamin Ruit, por valor de 111.822 reales $^{18}$. En la primavera de ese año Benjamin compró 2.500 arrobas de lana y 500 de añinos a Francisco Martínez de las Heras, vecino de El Barco, por un total de 122.500 reales (a 39 y 50 reales la arroba respectivamente) las cuales habían de ser transportadas por el propio de las Heras hasta Villacastín, donde Ruit tenía su lavadero. Un tal Francisco Gómez Sandín, a sueldo del inglés, ejecutaba el negocio, que al final resultó ser ligeramente superior, con 2.576 arrobas de lana, 524 de añinos y un precio (que en el mes de septiembre ya se había pagado) de 126.664 reales. La lana, una vez comprada y lavada, sería trasladada a Bilbao ${ }^{19}$. Al mismo tiempo, el inglés cobraba letras de cambio en nombre de sus colegas Richard Suit y Nicolas Joanes, otorgaba poderes para cobrar géneros que se le debían tanto en España como en Francia ${ }^{20}$, y cerraba la venta de 142 arrobas de salmón por 2.992 reales, y la de 13.132 libras de cera amarilla por la suma de 58.496 reales $^{21}$.

En febrero de 1635 compró sus primeras propiedades inmobiliarias en Madrid: una casa en la calle de las Minas y Pozas (junto a San Bernardo), dos solares cerca del convento de Maravillas y una casa pastelería en el Postigo de San Martín. Tras conocer que los propietarios de esos inmuebles (los pasteleros Jusepe de Gálvez y María Bautista) habían fallecido y tenían deudas pendientes y acreedores deseosos de cobrar, Benjamin entró en la puja para hacerse con esas propiedades a través de un testaferro llamado Juan Francisco Tesa. La puja y remate de Ruit quedó en 123.000 reales, incluidos los 250 ducados de renta para la memoria de misas que habían mandado fundar los

16 AHPNM, Protocolo 4.671, fol. 627.

17 AHPNM, Protocolos 4.672-4.675 y 3.924.

18 AHPNM, Protocolos 7.172, fols. 85v, 164v, 379v, 406v; 7.173, fols. 93v, 232v, 249v, $250 \mathrm{v}, 289 \mathrm{v}, 538 \mathrm{v}, 539 \mathrm{v}, 600 \mathrm{v}, 601 \mathrm{v}, 603 \mathrm{v}, 650 \mathrm{v}, 736 \mathrm{v}$.

19 AHPNM, Protocolos 7.172, fols. 200v, 384-386v, 387-388r y 7.173, fols. 152-153v y $199 \mathrm{v}$.

20 Como el entregado en 29 de abril a su hermano Ezequiel Wright para cobrar a dos capitanes ingleses vecinos de Londres 4.800 reales. AHPNM, Protocolo 7.172, fol. 336v y 410v.

${ }^{21}$ AHPNM, Protocolos 7.172, fols. 336v, 410v, 442v, 450v, 451v y 7.173, fols. 281v, $283 \mathrm{v}, 284 \mathrm{v}, 285 \mathrm{v}, 286 \mathrm{v}, 291 \mathrm{v}, 297 \mathrm{v}$ y $298 \mathrm{v}$. 
difuntos en su testamento, así como diferentes censos de menor cuantía que pesaban sobre los inmuebles. Una vez ejecutada la operación, Benjamin arrendó la pastelería por 300 ducados anuales ${ }^{22}$.

Durante el curso de ese mismo año vendió ropa inglesa por valor de 98.010 reales ${ }^{23}$, y compró lana en Aliseda y Cáceres por valor de 35.700 reales, en Santibáñez (Cáceres) por valor de 18.150 y en Lumbreras (La Rioja) por $68.400^{24}$. En total, invirtió en lana una cifra cercana a 20.000 ducados. También pagó letras que sus compatriotas habían girado sobre él desde distintos puertos peninsulares, como por ejemplo una de 52.000 reales a nombre de Abraham Ruiter, residente en Bilbao, por la lana que había adquirido de un productor segoviano ${ }^{25}$. En aquellas fechas Benjamin ya tenía un cajero a su servicio, llamado Lucas Vicente San Juan ${ }^{26}$.

Sus relaciones con la tesorería de la junta del almirantazgo fueron cada vez más fluidas, al erigirse en depositario de las cantidades a que sus compatriotas fueron condenados en los distintos puertos cada vez que les fueron aprehendidas mercancías de contrabando. Para entonces un nutrido grupo de mercaderes ingleses, compuesto por Guillermo Pauley, Ricardo Suit, Petruen Cuaton, Jofre Inkleton, Arthur Orichur, Abraham Ruiter, Nicolas Joanes, Esteban Stoques, Thomas Lebreton y Marmaduke Rawdem entre otros, se había especializado en la introducción de mercaderías, tanto de Inglaterra como de Francia, por los puertos del Norte, por Portugal y sus islas, y ocasionalmente también por Andalucía y las Canarias. Desde Madrid, Ruit pagaba las letras que éstos daban sobre él para comprar mercancías confiscadas, o recomprar las que a ellos mismos les habían embargado los veedores de la Junta. En estas ocasiones Benjamin supo negociar con habilidad, al descontar de dichas letras los gastos de conducción del dinero y a veces otros relativos a los cambios, cuyo montante dependía de si el abono se hacía en plata o en letra con valor en plata. En 1633 abonó «por letras que sobre él habían dado» cerca de 70.000 reales procedentes de las confiscaciones del navío El Sacrificio de Abraham, que había sido detenido y condenado en Bilbao ${ }^{27}$. De esas letras, el señor Ruit reducía un 8,5 por ciento en concepto de «interés y premio de remitir las cantidades en letra», cuando el precio normal de la conducción oscilaba entre un tres y un cinco por ciento ${ }^{28}$.

22 AHPNM, Protocolos 3.926, fols. 66-68v, 188r y v. 224-225, 229-230v.

23 AHPNM, Protocolo 7.175, fols. 16v, 20v, 54v, 71v, 163, 167v, 177-178v, 264v, 265v, 266v, 330v, 333v, 404-405v, 431v, 432, 433, 573v, 722v.

${ }^{24}$ AHPNM, Protocolo 7.175, fols. 406-409v, 493-494v, 529v, 341v, 739-734v, 1.009$1.010 \mathrm{v}$.

25 AHPNM, Protocolo 7.175, fols. 477 y 478v.

26 AHPNM, Protocolo 3.926, fols. 66-68, 122-123, 188v, 229-230v.

27 ALLOZA, 2006: 132.

28 ALLOZA, 2006: 130. 
A pesar de la coyuntura favorable, los ingleses no pudieron evitar algunos obstáculos y dificultades en el desenvolvimiento de sus negocios, unas veces debido al celo excesivo de los ministros de justicia en puertos y aduanas, y otras a los intentos protectores de la industria doméstica por parte de las autoridades municipales. En agosto de 1634 Benjamin Ruit y Guillermo Pawley fueron denunciados en Segovia, junto a los arrieros que transportaban las cargas de bayetas y lienzos que desde Bilbao encaminaban a Madrid, por impago de los debidos derechos y por utilizar un tinte de poca calidad en los tejidos. Los cargos no tenían fundamento alguno, como más tarde se comprobaría ante el corregidor de la ciudad, lo que no impidió la sentencia condenatoria al pago de 6.000 maravedís y costas, con apercibimiento de que en adelante deberían teñir las bayetas de azul, y no de negro. Los mercaderes recurrieron en la Chancillería de Valladolid, instancia que en poco tiempo revocó la sentencia del corregidor de Segovia y absolvió a los reos ${ }^{29}$.

\section{BENEFICIARIO DE LICENCIAS DE CONTRABANDO}

En 1636 Benjamin se hallaba en Madrid, continuaba comerciando con tejidos y negociando con letras de cambio. Cobraba las remitidas de Ciudad Rodrigo, Barcelona, Amberes y Sevilla; y pagaba las emitidas desde Sevilla, Cádiz, Bilbao, Segovia, La Laguna y Málaga. Compraba lanas y era cesionario de varios tratantes. En el mes de octubre dio poder a Jofre Inkleton, Robert Tinley y Lucas Vicente para efectuar algunos negocios, por lo que se deduce que abandonó la capital temporalmente, al menos hasta abril de 1637. También hay constancia de que mantuvo contactos con su hermano Nathan Wright en Londres. En estas fechas la carrera de Benjamin iba a experimentar un cambio vertiginoso, una aceleración exponencial que no pararía ya hasta la bancarrota de 1647, con caída no menos vertiginosa y traumática. En efecto, a contemplación de don Walter Aston, embajador inglés en Madrid, el 14 de octubre de 1636 se concedió a Benjamin Ruit licencia para introducir por los puertos de Bilbao y Cádiz hasta 200.000 ducados de plata en lencería francesa, pagando a la real hacienda un cinco por ciento de dicha suma, no obstante la prohibición general que pesaba sobre las mercaderías de aquel reino ${ }^{30}$. Los 10.000 ducados que costaba la licencia serían pagados por Benjamin con gé-

29 Ejecutoria en forma ganada a petición de Guillermo Pauler y Benjamin Ruita, residentes en la villa de Madrid, febrero 1636. ARCHV, Registro de Ejecutorias, caja 2.628, 0002. Existen otros ejemplos de denuncias sobre bayetas inglesas contra Ruit, como la que se inició en Miranda de Ebro en agosto de 1633. AHPNM, Protocolos 2.504, fol. 302-v y 3.925, fols. 288-289.

30 AGS, Contaduría del Sueldo, segunda serie, legajo 159. 
neros destinados al equipamiento de los soldados que más tarde iba a transportar a Flandes, esto es, con 4.000 capotes de campaña de paño ordinario de La Parrilla y 4.000 pares de medias del mismo tejido, valorados en 184.000 reales de vellón ${ }^{31}$.

Con objeto de paliar los déficit de grano, cobre, pertrechos navales y manufacturas textiles que las rupturas bélicas y subsiguientes bloqueos comerciales provocaban, los gobiernos de los Austrias recurrieron a la expedición de licencias especiales para introducir mercadurías de contrabando, esto es, géneros que pese a estar vetados por las leyes se permitía su entrada de una forma regulada, sujeta a restricciones de cantidad y género, y previo pago a la real hacienda de una cantidad fijada de antemano por el beneficiario de la licencia, que oscilaba entre un cinco y un 15 por ciento del valor de las mercancías a introducir. Entre 1637 y 1640 se concedieron permisiones por un valor de 4.388.000 ducados, quedando para la real hacienda 438.873 de beneficio $^{32}$. De esa enorme cantidad en licencias expedidas, cerca de una cuarta parte fue a parar a manos de Benjamin Ruit.

En julio de 1638 se le otorgó una permisión para introducir 400.000 ducados de mercaderías de fábrica de Francia, bastimentos y pertrechos por los puertos de Bilbao y San Sebastián, y por la cual hubo de pagar 40.000 ducados en plata aquel mismo mes de julio ${ }^{33}$. Benjamín solicitó permiso para introducir las mercancías por algún otro puerto distinto de los señalados, y exigió que no le molestase ningún veedor de comercio, y que no se concediera permisión alguna a otros mercaderes para introducir géneros por los mismos puertos que figuraban en la suya, al menos hasta que no expirase el plazo fijado en ella, que era de 20 meses. Cuando apenas llevaba introducidos 70.000 ducados en mercaderías francesas, el monarca otorgó licencias a otros comerciantes, por lo que Ruit solicitó la devolución de las cantidades que había pagado a cuenta de los 40.000 ducados que costaba la suya. Solo consiguió que el consejo de hacienda le concediera 10 años de plazo de ejecución en vez de los veinte meses que en un principio prescribía. A esta permisión habría que sumar otras que le llegaron por diferentes vías, como la de 20.000 ducados que le cedió Gaspar de Toledo, u otra expedida en noviembre de 1637 por cuantía de 150.000 ducados.

Pese a la probada capacidad del señor Ruit para los negocios, resulta difícil imaginar que pudiera hacerse cargo de tan enorme volumen de trabajo, pues la letra pequeña de las licencias, siempre concisa pero al mismo tiempo sujeta a interpretaciones caprichosas de las diferentes instancias jurisdiccionales establecidas alrededor de los puertos, hacían prácticamente imposible ejecutar

31 AHPNM, Protocolo 7.187, fols. 309v y 349v, 705-706 y 724-725.

32 ALLOZA, 2006: 141.

33 AGS, Contaduría del Sueldo, segunda serie, legajo 159. 
las licencias en su totalidad en los plazos fijados. Por estas razones, Ruit cedió parte de sus licencias a algunos compatriotas, como se aprecia en el cuadro adjunto, cuyos datos corresponden a la permisión de los 400.000 ducados.

CuAdro I: Cesionarios de las liCENCIAS ESPECIALES DE BENJAMIN Ruit (1638)

\begin{tabular}{lllc} 
MERCADER & NACIÓN & PUERTO DE OPERACIÓN & $\begin{array}{c}\text { DUCADOS } \\
\text { PERMISIÓN }\end{array}$ \\
\hline Nicolas Dun & inglés & Bilbao & 10.000 \\
Juan Escon y Jofre Inkelton & inglés & Cádiz & 150.000 \\
Prestuiq Eaton y Timoteo Aslope & inglés & San Sebastián & 15.000 \\
Thomas Beston y Juan Rome & inglés & Bilbao & 10.000 \\
Nicolas Joseah & inglés & Bilbao & 15.000 \\
Jorge Jifrite & inglés & Bilbao y San Sebastián & 15.000 \\
Hugo Cadroque & & Cádiz & 50.000 \\
\hline
\end{tabular}

Fuente: AHPNM, Protocolo 7.183, fols. 8v, 12, 134v, 236v, 331v, 460v, 461v, 462v, 363, 366-367

A las complejidades existentes en puertos y aduanas para ejecutar en tiempo y forma las licencias, se unía el contrabando realizado en barcos ingleses. Este comercio ilícito menoscaba el sistema de licencias en el que Ruit se hallaba involucrado de lleno, y que en la práctica operaba como una estructura de pequeños monopolios. El año de 1639 fue un caso ejemplar en este sentido; ante la acuciante necesidad de trigo en la península Ibérica, Francia optó por derogar las prohibiciones que pesaban sobre sus súbditos para vender cereal en España, pero como los mercaderes franceses no podían acercarse a las costas españolas por el riesgo de sufrir el embargo de sus navíos y cargazones, el transporte del trigo francés se llevó a cabo en barcos ingleses y por vía de contrabando. En un intento por proteger sus inversiones, Ruit se puso en contacto con el embajador inglés en Madrid, ahora Arthur Hopton, pidiéndole que intercediera ante Carlos I Estuardo para que pusiera fin a dicho comercio ilícito. Hopton confirmó la existencia de ese comercio fraudulento francés por mano de ingleses, pero no hizo nada para evitarlo ${ }^{34}$.

Los negocios en los que Ruit se introducía eran cada vez más complejos y de mayor envergadura, pero el viento soplaba a su favor. En 1638 vivía en la céntrica calle de San Ginés, tenía un cochero y dos criados que le asistían. Pagaba un censo de 2.000 ducados de principal a Francisco Salazar por la

34 KEPLER, 1976: 66. TAYLOR, 25/2 (1972): 236-260, 254. 
casa que había adquirido recientemente, y compraba cebada para la caballeriza que compartía con el embajador inglés ${ }^{35}$. Actuaba como apoderado de varios mercaderes ingleses que residían en Inglaterra y en España indistintamente, como Arnaldo Braems en Dover, el escocés Diego Brun y otros ${ }^{36}$. Simultáneamente compraba lana en Vinuesa (Soria) y Molina de Aragón (Guadalajara) por valor nada menos que de 320.000 reales $^{37}$, y negociaba con letras de cambio que giraban sobre él numerosos compatriotas desde distintos puntos de la península e islas Canarias. En 1639 le vemos viviendo en la calle Arenal, no obstante la casa que había adquirido recientemente en la calle de los Jardines, la cual acabó arrendando por 1.400 reales al año.

\section{FACTOR DEL REY}

En marzo de 1639 salió de Madrid con destino a Cádiz y Málaga por «cosas tocantes al servicio de Su Majestad». Esas «cosas» se referían a tareas relativas al transporte de soldados a Flandes e Italia, las mismas que le harían trasladarse en primavera a San Sebastián y Bilbao. La situación internacional era de lo más complicada, y esas operaciones precisaban de un ejecutor cualificado en los negocios y que se manejara con solvencia en lengua inglesa y con armadores y capitanes de esa nación, pues el canal de la Mancha se había convertido en la vía principal para el transporte de los soldados y la plata que se necesitaban en la ofensiva sobre las Provincias Unidas. Es cierto que esa vía, con escala en Dover, ya había comenzado a utilizarse tiempo atrás ${ }^{38}$, y que desde 1634, tras la firma de los artículos redactados entre el embajador español en Londres (Necolalde), y Lord Cottington, consejero de Carlos I Estuardo, trató de establecerse algún tipo de alianza hispano-inglesa para frenar las agresiones de franceses y holandeses en el canal. Para conseguir esos objetivos se pensó por ambas partes en levantar una armada fuerte y poderosa que abriera los puertos y prohibiera todo tipo de depredaciones en aquellos mares, al tiempo que asegurase las costas de Flandes. El primer recibo para el cobro del Shipmoney, aquel impuesto que tanto rechazo concitó y que estuvo en el origen del estallido de la Revolución inglesa, estaba asociado a esas negociaciones secretas ${ }^{39}$. El tratado Cottington-Necolalde fue firmado pero incumplido por ambas partes, lo que no impidió la colaboración de ambos reinos.

35 AHPNM, Protocolos 7.184, fols. 266v, 614v; 7.182 fols. 649v, 659v, 693v; y 8.183 sf.

36 AHPNM, Protocolos 7.182, fol. 315v y 7.183, fol. 571.

37 AHPNM, Protocolos 7.182, fols 432-433v, 732-733v, 7.183 fols. 560v., 7.184, fol. $459 \mathrm{v}$.

38 KEPLER, 1976.

39 ANDREWS, 1991: 128-147. 
De este modo, en el transcurso de aquellos años, tres grandes expediciones navales de socorro fueron enviadas desde la península Ibérica a Flandes con protección inglesa: la dirigida por el marqués de Fuentes en 1636, la que acudió a las órdenes de Lope de Hoces en 1637 y la comandada por Oquendo en $1639^{40}$. En esta última, que fue la que mayores complicaciones sufrió, participó muy activamente Benjamin Ruit, tanto en la consecución de los navíos armados ingleses, como en el transporte de los soldados debidamente alimentados y equipados.

El primer contrato de Benjamin Ruit en este nuevo negocio lo firmó el 26 de febrero de 1639. En el asiento se comprometía a conducir «por su cuenta y riesgo» 1.500 hombres de Cádiz a Dunkerque, y se estipulaba que por cada persona que fuese embarcada, la real hacienda había de pagar 337 reales de plata doble para el pasaje y sustento, desde su embarque en Cádiz hasta su desembarque en Dunkerque. En esta ocasión la junta de armadas se encargaba de entregar los navíos necesarios, «de los que tenía embargados», para el 15 de abril, y en caso contrario se haría cargo de las penalizaciones pertinentes (500 reales por día y navío). El monto total de la operación se elevaba a 505.500 reales de plata, cuyo pago sería una parte de contado, mientras la otra, que ascendía a 256.039 reales de plata doble, se le canjearía por lo que Benjamin aún debía a la real hacienda «de resto de los 40.000 ducados que montó el asiento de la licencia de 400.000 ducados» que se le había otorgado poco antes ${ }^{41}$.

En un segundo asiento firmado días después, 14 de marzo, Benjamin se comprometía a trasladar 3.500 infantes desde La Coruña a Dunkerque, obligándose la real hacienda a pagar 300 reales de plata doble por el pasaje y sustento de cada uno, lo que sumaba un total de un millón y medio de reales. Incorporaba, además de las cláusulas de rigor, una licencia de saca por valor de 600.000 reales. Pero a diferencia del asiento anterior, en esta ocasión los libramientos que se fijaron a Benjamin Ruit eran mucho más volátiles, porque aunque 16 millones de maravedís habían de abonársele de contado, el resto se le libraba en los arrendadores de las salinas de Atienza (10 millones de maravedís), a pagar en el mes agosto, otros cinco millones en el de Murcia, en el mismo plazo, algo más de uno en el de Espartinas, y los casi 17 restantes en los arrendadores de Galicia y Asturias, pero para no cobrar estos últimos hasta octubre. En este nuevo contrato, a cambio del adelanto de dinero, Ruit se benefició del buen tratamiento que se le hizo en intereses por días de demora, en comisiones, trueques de vellón y otras bagatelas de la factoría, como el no incurrir en pena alguna «por trocar el vellón de las dichas consignaciones a plata a mayor precio de la pragmática», o el conseguir para su licencia espe-

40 ALCALÁ ZAMORA, 2001: 212-214.

41 AGS, Contadurías Generales, legajo 133-1 y AHPNM, Protocolo 7.185, fols. 173-173. 
cial de 400.000 ducados interesantes condiciones y prerrogativas, como la de evitar que los veedores de contrabando se incautasen de las mercancías que introducía sin comprobar fehacientemente que eran de origen holandés ${ }^{42}$. Por lo demás, era tanta la necesidad de navíos, que en esta ocasión se autorizó a Benjamin a que emplease buques holandeses si lo estimaba preciso, a condición de que fueran navegados por maestres ingleses.

Aquel mismo mes de marzo de 1639 firmó en Madrid un tercer asiento para transportar 4.200 hombres: 3.000 de Cartagena a Dunkerque y 1.200 a Pasajes (Guipúzcoa); de éstos últimos, 250 serían llevados desde Ceuta, 250 desde Tánger, 200 desde Larache, 200 desde la Mamora y los 300 restantes desde Orán, si bien se obligaba a colocar otros tantos gastadores en cada una de las referidas plazas de África. En esta ocasión corría por su cuenta y riesgo el fletar, buscar y pagar los bajeles para la operación. Por cada soldado transportado a Dunkerque se le pagarían a 400 reales de plata doble, lo mismo que por los de Orán, mientras que el resto correría a razón de 350. En total, la operación alcanzaba una suma de 1.635.000 reales de plata doble, a lo que había que sumar 608.000 de reducción a plata, gratificación e intereses, sumando finalmente 2.243.000 reales. El pago se efectuaría de manera similar a la anterior: 515.000 de contado cuando estuviesen listos los navíos, y el resto en las salinas mencionadas y con los mismo plazos. El 2 de abril de 1639 firmó un cuarto y último asiento para conducir 5.000 hombres desde los puertos de Cartagena, Málaga y los Alfaques a Génova, pero no disponemos de mucha información más sobre este contrato, tan solo que para efectuar la operación dio poder a su compatriota Giles Feetplace, residente en Cartagena ${ }^{43}$. En suma, durante el año de 1639 Benjamin Ruit firmó cuatro asientos con la junta de armadas para transportar un total de 14.200 soldados a Flandes e Italia.

Desde comienzos de ese año de 1639 se habían expedido órdenes para la construcción de una flota de guerra de 25.000 toneladas. Paralelamente se había comisionado al proveedor de la armada para embargar cualquier bajel que conviniese al servicio real ${ }^{44}$. En marzo Benjamin se había trasladado a Cádiz y Málaga para ejecutar su primer asiento. Al poco estaba de vuelta en la corte, pero solo para continuar su viaje a San Sebastián, Bilbao y Santander, con objeto de contratar allí buques ingleses bien pertrechados para el cumplimiento del segundo asiento. Lo que ocurrió durante el verano de 1639, preludio de la destrucción de la flota de Oquendo en The Downs en otoño, no está investigado suficientemente, pero tuvo mucho que ver con los problemas a que hubo de enfrentarse Ruit a la hora de cumplir sus compromisos con puntualidad. Reconstruimos a continuación lo que hemos averiguado.

42 AGS, Contaduría del Sueldo, segunda serie, legajo 159.

43 AHPNM, Protocolo 7.187, 354-v.

44 ALCALÁ ZAMORA, 2001: 412-13. 
A fines de abril se contaban en La Coruña 5.802 infantes, que gastaban 8.599 reales diarios. Muy pronto llegarían 1.200 más. En mayo, Benjamin Ruit se hallaba en San Sebastián buscando y contratando barcos. Desde allí envió a La Coruña 12 navíos. En agosto envió siete más y cerca de 2.000 soldados y marineros ${ }^{45}$. En el canal de la Mancha las escuadras holandesas comandadas por Tromp acechaban a las expediciones anglo-españolas. Ante el evidente peligro, el almirante inglés Northumberland había prohibido a los mercaderes ingleses enviar barcos a España para cargar soldados y dirigirlos a Dunkerque, pero muchos de los maestres que solían realizar aquellas operaciones, liderados por el capitán Thomas Davis, desafiaron la orden y se dirigieron a España. A comienzos de mayo Davis decidió partir hacia Dunkerque con un cargamento de soldados y plata sin esperar a la partida de la flota española.

Cuando Davis y su flotilla se aproximaban al canal, los factores de Dover se alarmaron: 30 barcos holandeses habían sido vistos en las cercanías. Algunos de los factores pidieron que su dinero fuese protegido por el almirantazgo inglés, por medio de la Channel fleet, sin embargo Carlos I prohibió al almirante salir en busca de la flota de Davis. Lo que ocurrió con ella es incierto, pero un periódico de Londres publicó el 25 de junio que «cuatro barcos de Dover cargados con soldados españoles y un buen cargamento de plata proveniente del tesoro español habían peleado con 12 navíos holandeses en el estrecho, y tras cañonearse con dureza, los holandeses ofrecieron a los maestres británicos abandonar a los soldados españoles, a cambio de liberar los marineros y la plata que transportaban (lo que parece que ocurrió). De acuerdo con Alcalá Zamora, en aquellas mismas fechas otros cinco navíos salieron de España, pero solo uno logró el objetivo de llegar sin incidentes a su destino, mientras que de los restantes se conoce que dos fueron interceptados y de los otros dos uno llegó a Plymouth y el otro a la isla de Wight. Tres de estos últimos navíos ingleses habían zarpado de Cádiz fletados por Benjamin Ruit, siendo capturados los 1.500 infantes napolitanos que transportaban ${ }^{46}$.

En julio, a instancias del embajador de Felipe IV en Londres, Alonso de Cárdenas, se decidió que los hombres de la flota de Davis y de los barcos arribados a la costa inglesa que habían logrado escapar de las garras de Tromp, pasasen en pequeños grupos de Dover a Flandes en embarcaciones regulares inglesas. Los Estados Generales de Holanda, usando el incidente de Davis como pretexto, pretendieron cerrar el paso a los barcos británicos que cargaban dinero para Flandes. De algún modo el apresamiento de la flota de Davis y sus consecuencias constituyeron el preludio de lo ocurrido meses después en The Downs. Cuando partió Oquendo de La Coruña el 9 de sep-

45 AGS, Estado, legajo 3.173, junta de armadas de 22 de agosto.

46 ALCALÁ ZAMORA, 2001: 414. 
tiembre aún se ignoraba lo que había ocurrido con los barcos de la flotilla de Davis. El «escuadrón Dunkerque» de la flota española de Oquendo llevaba casi todo el dinero y muchas de las tropas destinadas a Flandes. Ancló muy cerca de North Foreland, enfrente de Calais y Dunkerque. Tromp envió algunos barcos allí. El 11 de septiembre Pennington envió un correo a Tromp conviniéndole a que se abstuviera de adentrarse en aguas inglesas, y asegurándole que impediría que la flota española escapase por la noche. Tromp aceptó aguardar en aguas no inglesas, pero a la mañana siguiente descubrió que los 14 barcos del «escuadrón Dunkerque» habían huido precisamente durante la noche y alcanzado su destino con la plata y los soldados que transportaban. Tras acusar a Pennington de incumplir su palabra, a fines de octubre los holandeses destruyeron gran parte de la flota de Oquendo.

Por diferentes problemas, y no solo por los registrados en el canal de la Mancha, Benjamin no pudo cumplir con todo lo asentado, por lo que hubo de devolver algunas de las cantidades que se le habían librado para ejecutar las factorías. También hubo de enfrentarse a un pleito iniciado por el fiscal del consejo de guerra, Francisco de los Herreros. Por lo que se conoce, en unas ocasiones no pudo reunir todos los soldados necesarios, en otras faltaron barcos y en las más de ellas los plazos fijados hubieron de ser ampliados. Con todo, Benjamin ejecutó una gran parte de lo que estuvo en su mano, no pudiendo ejecutar la totalidad por causas que escapaban a su control, como se demostró en el pleito mencionado, del cual salió absuelto por sentencia de vista y de revista ${ }^{47}$.

Los problemas en el canal de la Mancha y los registrados en los puertos peninsulares a la hora de reunir la tropa y barcos necesarios para su transporte ciertamente impidieron la ejecución completa, por ambas partes, de lo acordado. No obstante, a pesar de la complejidad de la documentación estudiada, hemos podido reconstruir una parte de lo que sí se ejecutó de los dichos contratos. Del asiento firmado el 14 de marzo de 1639 para conducir 3.500 infantes de La Coruña a Dunkerque, por el que se habían librado a Benjamin Ruit 48.780.500 maravedís, el factor logró embarcar 1.720 infantes en ocho bajeles que había encaminado a Galicia desde los puertos de Cantabria, «en conserva de la Armada que sacó de la Coruña don Antonio de Oquendo», de modo que según las cuentas de Juan Lucas Manzolo, contador de la junta de armadas, Ruit tenía que devolver 23.450.208 maravedís, unos de contado y otros de las libranzas que se le habían efectuado en los arrendadores de las salinas de Murcia ${ }^{48}$.

Conocemos asimismo las sumas que se le libraron para la ejecución de las factorías: el 13 de marzo recibió 20.000 escudos en plata del banquero Julio

47 AGS, Contadurías Generales, Contaduría de Relaciones, tercera serie, legajo 1.710.

48 AGS, Contadurías Generales, legajo 133-1. 
Lucas Palavesín a cuenta del asiento de transporte de 3.500 infantes a Dunkerque $^{49}$. El 7 de abril siguiente le fueron librados por el mismo 8.000 ducados más ${ }^{50}$. El 16 de abril recibió 70.000 reales de plata en razón del asiento de los 5.000 soldados destinados a Génova ${ }^{51}$, mientras que el 20 de mayo anotó haber recibido 5.000 escudos del secretario Pedro de León, si bien desconocemos a qué asiento iban destinados ${ }^{52}$. El 18 de junio anotó un nuevo ingreso, esta vez de 98.000 reales de vellón, efectuado por Palavesín para a completar el pago del asiento de los 3.500 infantes ${ }^{53}$.

Por lo que respecta al primer asiento, el 13 de marzo recibió de Pedro de Villanueva, secretario de Su Majestad, 505.500 reales en plata, especificándose en la libranza cada uno de los pagos que se hicieron ${ }^{54}$. Ese mismo día los mercaderes de ropería que se habían obligado con Ruit a suministrarle 4.000 capotes y 4.000 medias de paño ordinario de La Parrilla, recibieron de Benjamin 184.000 reales de vellón por la mercancía ${ }^{55}$, la cual entregaría luego al secretario Villanueva, liquidando así el pago por la licencia de contrabando que se le había concedido a fines de $1636^{56}$. Y ese mismo día, quizá aprovechando su visita al notario, Benjamin dio poder a su compatriota Duarte Chapel para embarcar los 3.500 infantes de la Coruña a Dunkerque y para que pudiera requerir al gobernador de aquella plaza el fletamento y embargo de los navíos que estimase necesarios ${ }^{57}$. El 3 de agosto recibió de Julio Lucas Palavesín otros 70.000 reales de plata ${ }^{58}$. Sabemos, finalmente, que en diciembre Benjamin Ruit otorgó poderes al general Jerónimo de Masibradi, por un lado, y al gobernador Martín Ladrón de Guevara y a Diego Cardoso, por el otro, para cobrar lo que le habían librado en los arrendadores de las salinas de Atienza, Espartinas y Murcia, al primero, y de Galicia y Asturias, a los segundos, devolviendo así la parte de la libranza del asiento los 3.500 hombres que no había logrado ejecutar, ya que sólo había podido embarcar, como vimos, 1.720 hombres $^{59}$.

Un dato más, registrado unos años más tarde, confirma lo expuesto hasta aquí. El 5 de junio de 1646 se vio de nuevo en el consejo de hacienda el pleito que se había tenido con Benjamin Ruit «sobre el incumplimiento del contrato

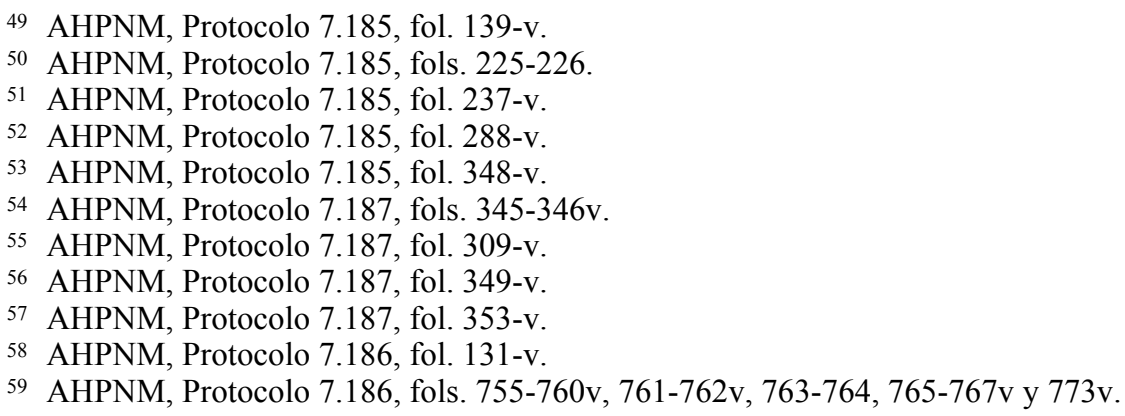


que firmó en 1639 para la conducción del traslado de 14.000 infantes a Flandes, Italia, África y otras partes», y del cual había salido ileso por sentencias de vista y de revista. En el apunte se explicaba que dicha «factoría había importado 4.790 .000 reales, de los cuales se hicieron algunas libranzas a Benjamin Ruit por valor de 877.000 reales ${ }^{60}$, cantidad que viene a coincidir con los libramientos que hemos descrito en los párrafos anteriores, y que sobre todo confirma que se le libró apenas una sexta parte del importe total de la misma.

\section{Asentista de Felipe IV}

Benjamin, qué duda cabe, era ya un hombre importante en Madrid. En enero de 1642 concertó matrimonio con Jacinta María de Chiriboga Córdova y Aragón, una noble madrileña que aportaba al matrimonio nada menos que una dote de 20.000 ducados y que muy pronto le daría una hija, lo que desmiente la afirmación de Clarendon de que la esposa no aportó a la casa de Ruit sino su noble sangre. En el transcurso de ese mismo año de 1642 Felipe IV le hizo merced del hábito de Santiago ${ }^{61}$, y a comienzos del siguiente se intitulaba asentista de Su Majestad. Esto último fue en el verano de 1643. De sus negocios relacionados con la lana o con la importación y venta de tejidos ingleses ya no queda rastro. A partir de este momento su mundo serían las finanzas. El 1 de julio de 1643 el inglés firmó el primer asiento con Su Majestad, obligándose a colocar en Amberes 225.000 escudos (de a 50 placas). El segundo, por provisión extraordinaria, lo firmó el 30 de agosto de 1644, esta vez por 200.000 escudos repartidos en Flandes, Italia y Madrid. El tercer asiento se selló el 18 de octubre siguiente por un montante de 144.000 escudos. El cuarto fue de 237.000 escudos, firmado el 5 de septiembre de 1645, en esta ocasión para «Flandes y otras partes»; y el quinto y último se rubricó en septiembre de 1646 por un importe de 120.000 escudos. En total, durante aquellos cuatro años escasos, Benjamin se había comprometido no solo a prestar a Felipe IV la enorme suma de 926.000 escudos, sino también a colocarla en Amberes y otras diferentes plazas, a ser posible en reales de a ocho y de a cuatro castellanos ${ }^{62}$.

El negocio parecía desproporcionado para este mercader que no hacía más de diez años había recalado en Madrid realizando comercios cuyo volumen que ya era considerable- alcanzaba un par de decenas de miles de ducados. Sin embargo, tras examinar la ejecución de cada uno de los asientos que fir-

\footnotetext{
60 AGS, Contadurías Generales, Contaduría de Relaciones, tercera serie, legajo 1.710.

61 AHPNM, Protocolos 7.193, 7.194 y 5.292.

62 AGS, Contaduría Mayor de Cuentas, tercera época, legajo 67.
} 
mó, así como el despliegue de su incipiente negocio de banca, puede comprenderse en parte cómo pudo abrirse camino en una operación de tamaña envergadura. No resta importancia el hecho de que ninguno de los asientos que firmó llegase a ejecutarse en su totalidad, pues el volumen del dinero que sí logró colocar en Amberes constituye ya una empresa de consideración. Ni siquiera pensamos que Benjamin se introdujera en el mundo del crédito de la monarquía por iniciativa propia, antes al contrario pensamos -como Antonio Domínguez Ortiz y Carmen Sanz Ayán- que fue reclutado por el consejo de hacienda como otros pequeños financieros en los años cruciales de inicios de la década de 1640, en cuyo transcurso, como se sabe, algunos importantes banqueros genoveses abandonaron temporalmente sus posiciones, cediéndolas a otros hombres de negocios portugueses y flamencos, ante el temor a sufrir por enésima vez una bancarrota que estimaban cantada, y que -huelga decirlo- no tardó en llegar, lo que confirmó plenamente sus temores ${ }^{63}$.

Experiencia, como ha podido comprobarse, no le faltaba a Benjamin Ruit. Para sus anteriores negocios había tomado dinero prestado de diferentes sujetos y entidades, tanto en Madrid como en Plasencia o Toledo, o como en la propia ciudad de Baeza, a la que en la primavera de 1644 debía algo más de 40.000 reales que le había entregado por vía de emprésito para devolverlos a la llegada de los galeones ${ }^{64}$. Pero también dispuso de otras fuentes de financiación: doña Violante Correa, viuda de Fernando Tinoco, contribuyó con 121.047 reales al asiento de 200.000 escudos de provisiones extraordinarias que firmó Ruit ese año de 1644. El 5 de abril de ese mismo año Benjamin había dado poder a Guillermo Blonde y Cía, de Sevilla, para cobrar de la Casa de Contratación de Indias 150.000 reales de plata que todavía se le debían del asiento del transporte de gente para Italia ${ }^{65}$. Por tanto, poco a poco iba obteniendo dinero para colocarlo en Flandes según los requerimientos de los contratos firmados. En diferentes ocasiones el médico escocés residente en la corte, John Hamilton, había depositado en Benjamin Ruit sumas que superaban los 2.000 escudos de oro. Pero Ruit también recibió importantes cantidades de otros compatriotas suyos como Guillermo Pawley (20.000 reales), Susan Castelton, inglesa, viuda de Jacobo Badesford, que por aquellas fechas le reclamaba los 100.000 reales de vellón que le debía, o de Isabel Manuela de Visino, a quien tampoco había podido devolver en tiempo y forma los 22.400 reales que le había dejado en depósito a un interés del siete por ciento ${ }^{66}$.

Tras examinar la ejecución de los asientos de Ruit, las conclusiones que se

63 DOMÍNGUEZ ORTIZ, 1960. SANZ AYÁN, 219, LXV/1 (Madrid, 2005): 91-114; 2010, 17-34. ÁLVAREZ NOGAL, 2000: 429-456.

64 AHPNM, Protocolo 7.197.

65 AHPNM, Protocolo 7.197.

66 AHPNM, Protocolo 7.202. 
extraen resultan de lo más interesante, y no solo en lo que concierne a los negocios de nuestro protagonista, sino también a la compleja dinámica del crédito de la monarquía, pues como ha explicado Alberto Marcos, una cosa era lo que se asentaba y otra muy distinta lo que en la práctica se ejecutaba ${ }^{67}$. Esto es particularmente cierto en una coyuntura tan especial como la del período 1635-1648, repleta de conflictos en la monarquía. En este sentido, para poder cumplir con el primer asiento, Benjamin expidió letras a nombre de don Francisco de Melo, «gobernador de las armas de los estados bajos», por valor de 37.500 escudos en dos pagas (para los meses de enero y febrero de aquel año de 1643) y el resto (187.500 escudos) tendría que efectuarlo en pagas de marzo a diciembre a razón de 18.750 cada una. A cambio, por cada escudo de 50 placas, Benjamin recibiría 358 maravedís, hasta completar un total de 80.550 .000 maravedís en plata doble, «de peso, liga y valor con que se hicieron los asientos pasados»y. A esa suma de ochenta millones y medio de maravedís, que equivalía a los 225.000 escudos fijados en el asiento, habría que sumar 29.645.526 maravedís en plata y vellón «a buena cuenta de lo que podrían montar los intereses ( $8 \%$ anual en plata), premio de la reducción del vellón a plata, adehala (5\%) y conducción del asiento», montando principal y gastos la suma de 110.195.526 maravedís, lo que implicaba que el asiento de 225.000 escudos generaba unos costes de 79.055 escudos, es decir, el equivalente a un 37 por ciento del capital suscrito en el mismo ${ }^{68}$. Las libranzas de ese primer asiento -reproducidas literalmente de la información disponiblese efectuarían de la forma siguiente: 10,5 millones de maravedís en Madrid a comienzos de año, tres millones en las arcas de tres llaves de la tesorería general en seis pagas entre febrero y julio de 1643, 1,6 millones en vellón en dichas arcas a fin de enero y febrero, 16,8 millones en vellón en dichas arcas entre febrero y mayo, 25 millones en vellón en las mismas arcas entre julio y noviembre, 9,6 en lo mismo, 10,1 millones en los primer uno por ciento de 1644 y 1645, y finalmente ocho millones en vellón en el derecho del papel sellado ${ }^{69}$.

La primera paga por parte de Ruit se efectuó en tiempo y forma gracias a sus correspondientes en Amberes, Lionel Waque (o Leonel Ubaque) y Juan Corsam, que actuaban como paguistas de Ruit. Tras ese abono se hicieron otros, que en total sumaron 59.250 escudos, de los 225.000 que había firmado, más otros 250 escudos que se le reconocieron como gastos extra. Como quiera que el 1 de octubre de 1647, fecha de la publicación del decreto de suspensión de pagos, no se había acabado de cerrar este primer asiento, hubo

67 MARCOS MARTÍN, 2001, vol. 2: 15-39.

68 Desconocemos el premio que se aplicó y los gastos de conducción, aunque estos no debería ir más allá del 5 por ciento. ÁLVAREZ NOGAL, 2006: 205-232.

69 Sumado todo ello, la cifra no llega a los 110 millones que debería reflejar. 
de hacerse un rescuentro y calcular el cargo y la data del mismo, sumando comisiones y calculando los intereses de lo que se había efectivamente consignado. El rescuentro quedó de la siguiente manera: Benjamin proveyó 32.409.113 maravedís, a los que había que sumar 1.060.575 de adehala y otros 10.467.999 de intereses y premios hasta el día del decreto. En conclusión, por los 59.250 escudos de a cincuenta placas que Benjamin logró librar en Amberes, la real hacienda hubo de pagarle 90.556 escudos.

El segundo asiento, por importe de 200.000 escudos, se firmó en 30 de agosto de 1644. En él se comprometía a colocar 60.000 escudos de a 50 placas en la villa de Amberes entre marzo y diciembre de 1644, 40.000 escudos en Génova o Milán, a elección de Benjamin, y 100.000 más en Madrid, en la tesorería general. Por los 47.720.000 maravedís de plata y 22.666 .666 en vellón que sumaba la provisión total (200.000 escudos de a 350 maravedís en esta ocasión), la real hacienda habría de pagar 29.728.938 de intereses, premio de reducción a plata, conducción, adehala y gratificación, montando todo ello poco más de cien millones de maravedís, los cuales se le habrían de librar en Madrid (20.000 ducados en plata), en los galeones (10.000 ducados en plata), en réditos de juros de Su Majestad del año 1644 (124.000 escudos), en el servicio de millones de Ocaña, Alcalá y Toledo (44.000 ducados), en el servicio de excusado (10.974 ducados), en el de los millones de Sevilla (12.000 ducados), y en el de los de Madrid (46.000 ducados).

Por lo que hemos podido comprobar de la ejecución de este segundo asiento, Benjamin logró proveer al pagador de las armadas de Dunkerque 24.000 escudos por cuenta de los 60.000 a que se había obligado, y de cuya cantidad había dado letra el 23 de marzo de 1644; había provisto asimismo 7.453.335 maravedís en plata (valor de 20.000 escudos pagados en Génova y Milán) por cuenta de los 40.000 escudos que había de proveer en Italia, de cuyo importe había girado letra a pagar al marqués de Velada. Finalmente, en Madrid, en la tesorería general, logró colocar 19.432.305 maravedís, es decir, 55.500 escudos de los 100.000 que había firmado. En total, proveyó cerca de 36 millones de maravedís de los 47,6 millones de plata y 22,6 de vellón firmados, esto es, casi un 45 por ciento del capital fijado en el contrato, porcentaje que superaba ampliamente a lo consignado en el asiento anterior, que no llegó siquiera al 27 por ciento.

La devolución de los créditos por parte de la real hacienda revelaba un mundo aún más complejo que el de las consignaciones de los hombres de negocios, porque cuando se ejecutaba una consignación, es decir, cuando un hombre de negocios transfería y depositaba una cantidad de dinero, se registraba el abono y así quedaba resuelto el asunto. Por el contario, los libramientos que efectuaba la real hacienda para devolver lo que había tomado prestado, podían escriturarse, firmarse o registrarse de la manera más oficial que se quisiera, pero luego había que cobrarlos efectivamente, y ahí residía el problema, que muchas de estos libramientos se hacían sobre rentas y juros que a 
veces no tenían cabimiento suficiente, o que se habían secuestrado temporalmente, o incluso que habían quebrado y suspendido pagos, lo que implicaba retrasos muy perjudiciales para los hombres de negocios y también nuevos trámites burocráticos y notariales para recolocar dichos libramientos.

El 27 julio de 1644 Benjamin cobró de la real hacienda 241.027 reales, equivalentes a lo que valieron 29 barras de plata en pasta que se le libraron de contado «por cuenta de los 144.000 escudos de provisión general de 1644», correspondientes al tercer asiento. En septiembre se le libraron 44.000 ducados en diferentes pagas del servicio de millones en Ocaña, Alcalá y Toledo del año 1644, sin que sepamos a qué asiento correspondía ese libramiento ${ }^{70}$. En los almojarifazgos de Sevilla, sobre la primera y segunda cuarta parte de juros situados sobre esa renta, también se le pagó algún dinero aquel año de 1644, si bien en junio de 1646 todavía no lo había cobrado, pues en esa fecha en el consejo de hacienda se discutía cómo habían de pagársele los ocho millones y medio que aún se le adeudaban. La cuestión era realmente compleja, como exponía amargamente Benjamin Ruit en su misiva a los consejeros, porque a cuenta de esos libramientos que nunca acaban de llegar, él ya había girado diferentes letras, pensando que el cobro de los mismos era inminente. Aún peor, Ruit tuvo que soportar que otros banqueros, como Jorge de Paz Silveira, recibieran libramientos sobre los almojarifazgos cuando en realidad el portugués tenía cantidades menores que las de Benjamin libradas sobre aquella renta. Ciertamente, protestaba Ruit, el haber tenido que devolver letras a acreedores suyos afectaba muy negativamente a su crédito y reputación como banquero, pero más ofensivo había sido el perjudicarle a él para favorecer a otros, como hubieron de reconocer en hacienda ${ }^{71}$.

Del tercer asiento, firmado el 18 de octubre de 1644 por valor de 144.000 escudos, sabemos que logró hacer efectivos en Flandes 42.860 .000 maravedís, «por 120.000 escudos de a 50 placas que entregó en la villa de Amberes al pagador general Thomas López de Ulloa, de que dio cartas de pago de 12.000 escudos cada una ante el escribano Adrian Diereex». Esta cantidad consignada generó unos gastos de 8.041.618 maravedís, por lo que sumadas ambas cifras alcanzaban la de 51.001.619. Como quiera que a Benjamin se le devolvieron únicamente 48.018.153 maravedís, se produjo un alcance a su favor de 2.983.461. En todo caso, cabe destacar que en este asiento logró cumplir la mayor parte de lo firmado.

El cuarto se tomó el 5 de septiembre de 1645, esta vez para la provisión de 237.000 escudos en Flandes y «otras partes». Se inscribía dentro de las provisiones generales de aquel año, según el acuerdo del rey con su consejo de hacienda de 31 de diciembre de 1644. Las provisiones que firmó exactamente

\footnotetext{
70 AHPNM, Protocolo 7.200 sf.

71 AGS, Contadurías Generales, Contaduría de Relaciones, tercera serie, legajo 1.710.
} 
fueron: 178.500 escudos de a 50 placas en Amberes, 34.500 escudos de a 110 sueldos imperiales en la ciudad de Milán, y otros 16.000 escudos de a diez reales en Madrid y Sevilla. Por cada escudo de a 50 placas se pagarían a Ruit 358 maravedís, y por cada sueldo imperial provisto en Milán se le abonarían 372 maravedís y dos tercios de otro. Los escudos consignados en la corte se le pagaban a 340 maravedís. A los precios referidos, montaba la provisión 84.920.000 maravedís en plata y vellón, suma que con otros 38.077.000 maravedís de intereses, premios y adehalas, más el precio de unas libranzas de contrabando que se le habían otorgado, quedó en 123.067.000 maravedís. Dicha suma había de librársele en los galeones o flotas de Indias (31.600 ducados en plata) en reales de a ocho y de a cuatro, así como en medias annatas de juros y diferentes rentas reales, excusado, millones (octavo repartimiento de los dos millones), y algo en dinero de contado en la tesorería general. En conjunto, tan solo se le libraron 44.915.799 maravedís de los 55.465.538 que él había logrado proveer (cerca de 160.000 escudos), si bien a esa diferencia de 10 millones a su favor había que añadirle los 14.027.315 maravedís en concepto de adehalas, intereses, gratificaciones, premios, y licencias de saca. En suma, descontado el cargo (44.915.799 maravedís) de la data (77.510.451 maravedís) resultaba un alcance a favor de Benjamin Ruit de 32.594 .652 maravedís, de los cuales se le descontaron por alguna razón que desconocemos 6.009.193 maravedís, lo que en todo caso constituía un enorme alcance cercano a 75.000 escudos.

El quinto y último asiento ajustado por Ruit con el consejo de hacienda en febrero de 1646 fue firmado el 3 de septiembre. El contrato prescribía la consignación de 120.000 escudos sobre provisiones generales, y en él se comprometía a poner en Amberes 48.000 sueldos desde enero a diciembre de 1646, 48.000 en Milán en 12 pagas en dicho año, 16.000 en Madrid, mitad en plata y mitad en vellón, y 8.000 escudos en Sevilla a fin de 1646. A esos 120.000 escudos había que añadir 34.341 .500 maravedís de intereses, premios, adehala, conducción, gratificación y licencias de contrabando. En total montaba el asiento 77.573.500 maravedís, los cuales habían de librársele en diferentes rentas y partidas: galeones, media annata de juros, papel sellado, segundo uno por ciento, dos por ciento de lo arrendable, excusado e impuesto de los pescados frescos y salados. Benjamin logró proveer 18.062.694 maravedís, cantidad que apenas llegaba a la mitad de lo firmado, aún así generó unos costes de 7.642.832, si bien mucho menos fue lo que recibió a cambio, pues solo se le libraron ocho millones y medio de maravedís, lo que produjo un alcance a su favor de 17 millones (unos 48.500 escudos).

Entrado el año de 1647 la deuda de la real hacienda contraída con los banqueros alcanzaba la enorme suma de 13 millones de ducados. Un nivel insostenible de débitos que, como ha apuntado Carmen Sanz, con toda probabilidad se vería agravado por las sublevaciones de Nápoles y Sicilia. Tan pronto 
como el consejo de hacienda comprendió que era imposible devolver todo aquello, pues las rentas y servicios estaban comprometidos al menos hasta 1653, el fantasma de la suspensión de pagos sobrevoló por el consejo, cuyos miembros lo contemplaron como la única solución posible, justo como lo había sido otras tantas veces en el pasado reciente. No todos los hombres de negocios fueron incluidos en el expediente, pero es cierto que muchos de los excluidos (Octavio y Domingo Centurión, Jácome María Spínola, Juan Jerónimo Palavesín y Juan Esteban de Imbrea) se comprometieron a satisfacer las necesidades de crédito más inmediatas. Al final, por diferentes razones, de los más de 60 asentistas afectados por el decreto de octubre de 1647, solo una quincena hubo de sufrir realmente las consecuencias. Entre ellos se encontraba Benjamin Ruit ${ }^{72}$.

La complejidad constatada en el ámbito de los asientos dificultó la averiguación de las cantidades debidas por la real hacienda a los prestamistas incluidos en el expediente de suspensión de pagos. Lo único que se sabía era que el dinero se les devolvería en principal de juro de a veinte mil el millar en plata, con goce desde el día del decreto en adelante. Años más tarde, en 1656, con motivo del embargo que se efectuó sobre los bienes de ingleses que residían en España, la junta de represalias se incautó de los 66 millones de maravedís que según sus cálculos el erario regio debía a Benjamin Ruit ${ }^{73}$. En el consejo de hacienda se confirmó que Ruit tenía naturaleza en la corona de Castilla, por lo que no podía ser comprendido en la represalia; pero lo que aquí interesa de esta noticia es la cuenta que realizaron los contadores de la razón para calcular lo que se le debía realmente a Ruit en 1656. De hecho, como se deduce de estas pesquisas, diez años después de producirse la suspensión de pagos, no sabían a ciencia cierta si aquellos 66 millones de maravedís constituían todo el capital despojado al inglés por el decreto de marras.

Las averiguaciones que se hicieron en la contaduría mayor de cuentas contemplaban que con Benjamin se habían tomado cinco asientos sobre la provisión de diferentes cantidades. De las cuentas se desprendía un alcance a su favor de 66.237.153 maravedís de plata y 1.132.572 de vellón. Sin embargo, en aquel informe nada se decía de otros alcances que aún no se le habían pagado de las factorías efectuadas en 1639, ni - peor aún- de la satisfacción de 25.370.960 maravedís en plata que al parecer se le había hecho efectiva por cuenta de esos 66 millones $^{74}$. Por añadidura, tampoco le habían descontado de esa cantidad otras tres pequeñas libranzas que sumaban 4,5 millones.

72 SANZ AYÁN, 219, LXV/1 (Madrid, 2005): 91-114, 112.

73 AGS, Estado, legajo 2.983.

${ }^{74}$ Esos 25 millones se libraron por el principal de 1.267.548 maravedís de renta en el segundo uno por ciento de la primera y segunda situación y servicio ordinario y extraordinario de diferentes partidas. AGS, Estado, legajo 2.989. 
Hubo que esperar al año de 1682 para conocer de forma más precisa el dinero que la real hacienda había dejado a deber a Benjamin Ruit, así como lo que desde el día del decreto en adelante se le había ido abonando para su manutención y pago de la dote de su hija, más los intereses que habían generado las cantidades adeudadas. Gracias a un pleito que le interpuso uno de los $p a-$ guistas mencionados de Amberes, llamado Leonel Wake (o Leonel Ubaque), correspondiente de Ruit desde el comienzo de su andadura en Madrid, podemos conocer los detalles de los asientos con un poco más de precisión. En 1656 Leonel Wake tenía un efecto sobre Benjamin Ruit de 130.000 escudos, el cual le había sido embargado a Benjamin con motivo de la represalia mencionada $^{75}$. Ruit admitió la deuda contraída con su compatriota y colaborador, si bien la rebajó hasta los 70.000 escudos. Ante la solicitud por parte de Wake de que no se embargase a Ruit la deuda contraída con él para así poder cobrar lo que le debía, la junta de represalias estimó que dicha deuda procedía en gran parte de las anticipaciones y servicios que Leonel le había proporcionado en Amberes, pero además aclaró que tanto Ruit como Leonel Wake no habían de sufrir el embargo de sus bienes porque ambos tenían naturaleza en Castilla y Flandes respectivamente ${ }^{76}$. El litigio por la cobranza de la deuda no acabó ahí, ya que al margen de la cantidad que finalmente se estableciera como deuda de Ruit a Wake, el hecho cierto es que Benjamin no tenía dinero para pagarla.

A fines de la década de 1670 el litigio entre los Ruit y los Wake no se había resuelto aún, pero a comienzos del decenio siguiente los hijos y nietos de ambos lograron alcanzar un acuerdo para ponerle fin. Acuerdo que acarreaba la puesta al día de las cuentas de Benjamin con hacienda, y que hoy nos permite examinarlas de nuevo y confrontarlas con las registradas en los libros de la contaduría. Una vez examinadas y fenecidas las cuentas por los contadores de la razón de hacienda tras un minucioso rescuentro, la contaduría mayor comprobó que con Benjamin Ruit se habían firmado cuatro asientos para transportar 14.200 soldados a Flandes e Italia, y otros cinco para colocar en Flandes y otras partes 926.000 escudos. De acuerdo con ese análisis, que sumaba alcance tras alcance después de fenecer las cuentas, que añadía los intereses debidos y que expresaba las dudas pertinentes, la contaduría dictaminó el 4 de febrero de 1682 que los alcances que resultaban a favor de Benjamin Ruit sumaban 69.826.118 maravedís de plata el día del decreto, esto es, 199.503 escudos ${ }^{77}$.

75 ALLOZA, 2006: 173-174.

76 AGS, Estado, legajo 2.987.

77 AGS, Contaduría Mayor de Cuentas, tercera época, legajo 67. 
CUADRO 2: El DECRETO DE SUSPENSIÓN DE PAGOS DE 1647 SOBRE BENJAMIN RUIT

\begin{tabular}{llr} 
FECHA & AsIENTO/FACTORÍA & \multicolumn{1}{l}{$\begin{array}{l}\text { AlCANCE A FAVOR } \\
\text { DE RUIT } \\
\text { Maravedís plata }\end{array}$} \\
\hline 14/10/1639 & Transporte de 4.200 hombres a Dunkerque y Pasajes & 2.793 .611 \\
30/03/1639 & Conducción de 5.000 hombres de Andalucía a Génova & -1.051 .305 \\
30/03/1639 & Conducción de 3.500 hombres de La Coruña a Flandes & 6.661 .974 \\
27/02/1639 & Transporte de 1.500 hombres de Cádiz a Dunkerque & 2.635 .000 \\
$10 / 07 / 1643$ & Provisión de 225.000 escudos de plata en Flandes & 11.200 .569 \\
$18 / 10 / 1644$ & Provisión de 144.000 escudos de plata en Flandes & 2.983 .461 \\
$05 / 09 / 1645$ & Provisión de 237.000 escudos de plata en Flandes & 26.085 .459 \\
$30 / 08 / 1644$ & Provisión de 200.000 escudos de plata en Flandes & -3.082 .066 \\
$03 / 09 / 1646$ & Fenecimiento de la cuenta del asiento de 120.000 escudos & 16.966 .024 \\
\hline
\end{tabular}

Fuente: elaboración propia a partir de AGS, CMC, $3^{\mathrm{a}}$ época, legajo 67. Los alcances en negativo (a favor de hacienda) se reflejan en el cuadro, pero ya van descontados de los alcances a favor de Ruit.

\section{TRAS EL DERRUMBE}

El varapalo sufrido por el señor Ruit a causa de la suspensión de pagos fue tremendo. En lo sucesivo, además de atender las demandas de sus acreedores, muy perjudicados también por el decreto, lucharía para recuperar lo que la real hacienda le había dejado a deber. Aunque ignoramos casi todo sobre su vida personal, los escasos datos de que disponemos sobre su actitud y comportamiento ante situaciones difíciles resultan verdaderamente admirables, tan extraordinarios o más que su propia trayectoria. A comienzos de 1650, apenas transcurrido un año de la ejecución de Carlos I Estuardo en Londres, recibió en Madrid a los dos embajadores extraordinarios que había enviado un exiliado Príncipe de Gales: Edward Hyde (futuro Earl of Clarendon) y Francis Cottington, antiguo embajador inglés en Madrid. En otras circunstancias, esta visita hubiese sido preparada y celebrada como correspondía por el gobierno español, pero en aquellas fechas, en las que Felipe IV hacía lo imposible por mantenerse en la neutralidad con respecto al conflicto fratricida que se libraba en Inglaterra, y más teniendo en cuenta que también esperaba la llegada de un embajador enviado por el parlamento, llamado Anthony Ascham, el rey mantuvo una cierta distancia para no suscitar la desconfianza de unos y otros ${ }^{78}$. Benjamin Ruit se preocupó de alojarles y preparar la visita oficial al monarca español. También se ocupó de entretenerles y agasajarles, gastando nada me-

\footnotetext{
78 CÁRDENAS, 2011: 39-40.
} 
nos que 26.000 reales, los cuales nunca recuperaría, a pesar de las instancias que hizo para ello. Tampoco logró la intermediación que esperaba de los embajadores mencionados ante el rey de España para recibir satisfacción de sus deudas en alguna forma extraordinaria ${ }^{79}$.

De su generosidad no cabía duda alguna, como apuntó Clarendon en los párrafos que le dedica en The History of the Rebellion. Incluso se llegó a decir que Benjamin se ocupó de la manutención en la cárcel de los asesinos de Anthony Ascham, el residente enviado por el parlamento que nada más llegar a Madrid fue brutalmente asesinado. La simpatía de Ruit para con el bando royalist en la contienda que se libraba en Inglaterra no le impidió colaborar más tarde con la república y el protectorado, lo que hizo a través de la mediación de su hermano Nathan Wright, que durante el conflicto inglés se había decantado claramente por el bando parlamentario, como buen «new merchant» que era. Nathan era miembro de la Levant company, y mientras su hermano Benjamin progresaba en Madrid, él lo hacía en Virginia e islas del Caribe, habiendo operado antes en Nueva Inglaterra, Greenland y Terranova. Durante los meses más conflictivos en Londres, entre fines de 1641 y la primavera de 1642, Nathan formó parte del comité de seguridad pública de la City ${ }^{80}$. También sabemos que en los años 1654-1655 Benjamin mantuvo correspondencia con el secretario de estado inglés John Thurloe, muy próximo a Cromwell, informando, como espía, sobre todo lo que acontecía en España, e intentando por todos medios impedir la ejecución del «plan antillano» del protector, pues de efectuarse -advertía Ruit- los ingleses que residían en España sufrirían graves consecuencias, como en efecto ocurrió. Con tal colaboración, Ruit perseguía implicar al mismísimo Cromwell para que intermediase en su litigio con la hacienda española.

En efecto, a partir de 1654 el señor Ruit se convirtió en el correspondiente del parlamento inglés en Madrid, en el informante secreto de los acontecimientos más importantes que ocurrían en España, con particular atención a los que afectaban a sus relaciones con la república de Inglaterra, como el relativo a la incertidumbre generada por la flota inglesa de 160 navíos que tras la firma de la paz con Holanda quedaba libre y a la entera disposición del protector. «La gente aquí habla públicamente de que la gran flota inglesa tiene el

79 Al abandonar Madrid en marzo de 1651, Clarendon reconoció el buen servicio que le había prestado Benjamin Ruit, incluido el débito de 26.000 reales. Una vez en Amberes escribió a Carlos II Estuardo, que se hallaba en Escocia, urgiéndole a reconocer los servicios prestados por Benjamin en España y pidiéndole su mediación en Madrid. «Commencement of a memorial in the name of Sir Benjamin Wright, being a representation of his services to the Spanish Crown». Calendar of Clarendon State Papers in the Bodleian Library. Vol. II (16491654) Oxford, 1879, $\mathrm{n}^{\mathrm{o}} 199$ (addenda).

${ }^{80}$ BRENNER, 2003: 136, 151, 370, 379. 
designio de ir a Santo Domingo, en Indias Occidentales, enclave que dan por perdido. Si esto ocurre, las personas y haciendas de los ingleses que residen aquí serán secuestradas», advertía Ruit en su carta de 24 de octubre de 1654 . Como pago por sus informaciones, en mayo de 1655 Benjamin consiguió que Cromwell escribiese a Felipe IV instándole a la satisfacción de la deuda que hacienda tenía contraída con él, si bien el monarca español ni siquiera remitió la carta a los consejeros. No fue aquella la primera vez que se intercedía por Ruit desde Inglaterra: meses antes, en febrero de 1655, se reclamaron desde allí las sumas que se debían al señor Ruit derivadas de los préstamos que había efectuado en sus factorías y asientos. Sendos informes escritos desde Westminster, por el propio Cromwell, y desde el palacio de Vestmonat, por Olivier Prost, calculaban que se debían a Benjamin cerca de 90.000 libras inglesas, unos 360.000 ducados, y aunque la deuda estaba reconocida por la real hacienda y se le habían concedido diferentes cantidades en rentas reales en España, la misiva insistía en que el perjuicio hacia él, su familia y diferentes acreedores que tenía en Inglaterra era enorme ${ }^{81}$. Las intermediaciones sirvieron de poco, sin embargo con ellas Ruit había conseguido algo muy importante, que consistía en tener alguna presencia en los círculos de poder político de la república inglesa, y así le había informado el propio Thurloe en carta de 15 de febrero de 1655, en la que no solo acusaba recibo de todas sus misivas enviadas desde Madrid, sino que también le informaba de que eran muy estimadas por el propio Protector ${ }^{82}$.

El juego de doble agente a que se había sometido Ruit, le hacía sentir el acecho del peligro. Por esa razón, aunque Cromwell le hubiera tomado bajo su protección, Benjamin pidió al secretario Thurloe una credencial diplomática, aunque fuese secreta, a fin de poder usarla en caso de extrema necesidad, argumentando que «antes de que Su Alteza (Cromwell) tuviera noticia, aquí podría ser dictada una resolución inmediata contra mí, y mi cabeza cortada, pudiendo Su Alteza tomar luego satisfacción por el daño cortando dos cabezas, pero nunca poniendo de nuevo la mía sobre los hombros». Cuando a comienzos del verano de 1655 ya todo el mundo sospechaba que la armada de Blake no tenía otro designio que el de interceptar la flota de Indias, como el propio general se había encargado de explicar a algunos mercaderes ingleses residentes en Cádiz, Benjamin se encomendó a Dios y escribió a Thurloe expresando que ya su única esperanza consistía en conseguir algún empleo del Protector, y que para salir de España sin problemas necesitaría una carta de invitación recomendándole visitar Inglaterra, «pues esta gente -explicaba

81 BNE, Mss. 9.405 (116) y 9.926 (139-140).

82 A collection of the State Papers of John Thurloe. Thomas Birch (editor) 1742, Volumes 2 and 3, Sir Benjamin Wright to secretary Thurloe, Vol. xix. p. 277, Vol. xxvi. p. 14, Vol. xxv. p. 301, Vol. xviii. p. 92, Vol. xxvii. p. 119 y Vol. xxvi. p. 364. 
Benjamin- se echará encima de mí como una manada de lobos si los ingleses agreden las Indias o la propia flota, pues saben que me correspondo con usted $\rangle^{83}$.

Todavía en 1664 Benjamin persistía en sus intentos de obtener la intermediación necesaria para recuperar las enormes sumas de dinero que se le debían en España. En octubre de aquel año escribió al nuevo secretario de estado inglés, Henry Benet, para que le ayudara en sus propósitos, expresándose de esta forma: «mi esperanza es que el rey Carlos II me beneficie al menos con cartas de compensación contra los españoles. Estoy seguro de que yo las hubiera tenido si no hubiera sido desamparado por el gobierno de entonces, y haber recibido en mi casa a Lord Chancellor (Clarendon) y a Lord Cottington en el año 1650, entreteniéndoles durante meses a mi costa, mientras ahora no tengo para mantenerme a mí mismo». La despedida no podía resultar más emotiva: «Señor, en mis primeras cartas supliqué se acordara de mí e hiciera cuanto pudiera. Y si usted me da algún ánimo yo retornaré con el embajador, de otro modo un convento no me fallará para acabar mis días...» En abril siguiente Ruit escribió de nuevo a Henry Bennet comunicándole que iba a zarpar como capitán de lenguas en un barco de la armada española bajo el duque de Aveiro, por cuyo trabajo esperaba recibir 2.000 coronas al mes, «pues se hallaba en gran necesidad». Un año más tarde informó al secretario Bennet de que en efecto había estado 90 días en la mar, pero que debido a la muerte de Felipe IV, el duque había sido llamado a tierra, lo que aprovechó para abandonar la flota de Brasil.

Benjamin nunca cejó en el empeño de recuperar su dinero. A comienzos de 1667 solicitó a Carlos II hiciese merced a su yerno, Diego Fernández Tinoco, del título de Vizconde en Castilla o, en caso contrario, al menos le diese plaza en el tribunal de cuentas de la contaduría mayor de hacienda. Benjamin solicitaba este favor en consideración de lo que había servido a Su Majestad en materia de asientos, pero sobre todo de la nula satisfacción de sus deudas que en 18 años había recibido. En su memorial, visto en la cámara de Castilla el 5 de febrero de 1667, hablaba de alcances a su favor por unos 300.000 ducados, y reprochaba con acritud que ni siquiera se le hubiera ayudado con los 2.000 ducados de ayuda de costa que pidió tiempo atrás para ir a servir en la armada real. Tampoco perdió ocasión de mencionar la lealtad con que había servido mediante la asistencia a los embajadores españoles. Pedía esa merced para su yerno porque era él, a fin de cuentas, quien le alimentaba y mantenía en su casa. Y ni siquiera la pedía gratis, sino a cambio de lo que hubiera que pagar por ella, cargando el importe en cuenta de lo que la real hacienda aún le debía. La cámara rechazó ambas propuestas: la del vizcondado tenía «inconveniente por la estimación que se debía dar a estas dignidades», y Diego Ti-

83 Ibid. 
noco venía de familia portuguesa, probablemente con orígenes judíos, como - posiblemente- los del propio Benjamin. Por el título de vizconde ya había ofrecido en una ocasión anterior hasta 5.000 doblones, pero la cámara nunca «halló forma de entrar en ello». El puesto en el tribunal de cuentas tampoco era factible por el momento debido al excedente de ministros que había en el consejo de hacienda, cuyas plazas se amortizaban al producirse los ceses por exigencia de una ley dictada $a d h_{o c}{ }^{84}$. No obstante, poco tiempo después consiguió introducirse en el tribunal.

\section{BREVES CONCLUSIONES FINALES}

No cabe duda de que una coyuntura política internacional tan favorable para el desenvolvimiento de los negocios de mercaderes y armadores ingleses en España, como es la que se registró entre 1630 y 1648, impulsó la trayectoria de Sir Benjamin Wright. Sin embargo, como se ha tenido ocasión de comprobar, fueron su capacidad para los negocios y su audaz actitud ante los mismos los que convirtieron su carrera en extraordinaria y trepidante a la vez. Otros muchos mercaderes ingleses asentados en la península e islas Canarias, como Richard Houncel, Guillermo Pawley o Marmaduque Rawden desplegaron sus negocios y cosecharon muy buenos resultados, pero -en idénticas circunstancias- ninguno de ellos alcanzó el nivel económico y social que logró su compatriota Benjamin. Así pues, la carrera del señor Ruit constituye un ejemplo inmejorable de movilidad social ascendente en la época moderna, especialmente llamativo por tratarse de un inglés naturalizado, caso que no abundó precisamente a lo largo de la centuria ${ }^{85}$. Si bien, lo que ha llamado poderosamente nuestra atención, tanto incluso como su trepidante carrera, ha sido el hecho de que lejos de derrumbarse tras el varapalo de la suspensión de pagos de 1647, Benjamin luchara a fondo para recuperar su capital y posición, sin que ello le impidiese ponerse a trabajar como traductor, siendo ya mayor, en un barco de guerra, o que tras haberse codeado con las más altas magistraturas del estado y haber probado las mieles de la aristocracia, no vacilase en explicar nada menos que al secretario de estado inglés, rebajándose ad infinitum, que en caso de no lograr la ayuda que le pedía, un convento no le fallaría para acabar sus días en España.

Por último, el análisis pormenorizado de los asientos y factorías suscritos por Benjamin Ruit con la real hacienda durante aquellos agitados años, que ha desentrañado y desmenuzado en el nivel micro cada elemento del complejo mundo del crédito y las finanzas de la monarquía, pone de manifiesto las dé-

\footnotetext{
84 AHN, Consejos, legajo 4.440, expediente 9.

85 MARCOS MARTÍN, 2007: 19-47; DOMÍNGUEZ ORTIZ, 1992, vol. 1: 46-47.
} 
biles bases sobre las que se asentaban dichas actividades, así como los riesgos inherentes a las mismas que corrieron aquellos «nuevos» hombres de negocios que habían despuntado en las décadas centrales del siglo XVII; riesgos que interpretamos como un peaje inevitable a pagar por todos cuantos se dedicaban a servir a la monarquía en el ocaso de su esplendor. Finalmente, este minucioso examen ha descubierto un importante déficit de conocimiento en el mundo de las finanzas de la monarquía en esas décadas cruciales, al revelar que una buena parte de los asientos firmados por los banqueros nunca llegó a ejecutarse, lo que obliga a reconsiderar las cifras generales de deuda pública suscritas en las provisiones ordinarias y extraordinarias del periodo en cuestión.

\section{BIBLIOGRAFÍA}

Alcalá Zamora, José, España, Flandes y el mar del Norte (1618-1639), Madrid, CEPC, 2001 [1975].

Andrews, K. R., Ships, Money and politics: seafaring and naval Enterprise in the reign of Charles I, Cambridge, Cambridge University Press, 1991.

Alloza, Ángel, Europa en el mercado español. Mercaderes, represalias y contrabando en el siglo XVII, Valladolid, Junta de Castilla y León, 2006.

Álvarez Nogal, Carlos, "La transferencia de dinero a Flandes en el siglo XVII", en Carmen Sanz Ayán y Bernardo García García (eds.) Banca, Crédito y Capital. La monarquía Hispánica y los antiguos Países Bajos (1505-1700), Madrid, 2006; 205-232.

Álvarez Nogal, Carlos, "La estrategia de la real hacienda en la negociación del crédito de los Austrias", en Antonio Bernal (ed.) Dinero, Moneda y Crédito en la monarquía Hispánica, Madrid, 2000; 429-456.

Álvarez Nogal, Carlos, El crédito de la monarquía hispánica en el reinado de Felipe $I V$, Valladolid, Junta de Castilla y León, 1997.

Boyajian, J., Portuguese Bankers at the Court of Spain (1626-1650), New Jersey, Rutgers University Press, 1983.

Brenner, Robert, Merchants and Revolution. Commercial Change, Political Conflict, and London's Overseas Traders, 1550-1653, London-New York, Verso, 2003 [1993].

Cárdenas, Alonso, La Revolución inglesa (1638-1656), Ángel Alloza y Glyn Redworth (eds.), Madrid, Biblioteca Nueva, 2011.

Clarendon, Earl of, The History of the Rebellion and Civil Wars in England begun in the year 1641, Oxford, Clarendon Press, 6 vols., 1892.

Diago, Máximo, "Mercaderes y financieros ingleses en Madrid en tiempos de la revolución y guerra civil inglesa", AIEM XLIX (Madrid, 2009): 397-445.

Domínguez Ortiz, Antonio, Política y hacienda de Felipe I, Madrid, Pegaso, 1983 [1960]. 
Domínguez Ortiz, Antonio, La sociedad española en el siglo XVI, Granada, CSIC, 1992, 2 vols. [1963].

Fisher, F. J., "London's Export Trade in the Early Seventeenth Century", en W.E. Minchinton (ed.) The Growth of English Overseas Trade in the Seventeenth and Eighteenth Centuries, London, 1969; 64-77.

García Guerra, Elena y De Luca, Giuseppe (eds.) Il mercato del Credito in Età Moderna. Reti e operatori finanziari nello spazio europeo, Milano, Franco Angeli, 2009.

Gelabert, Juan Eloy, La bolsa del rey. Rey, reino y fisco en Castilla (1598-1648), Barcelona, Crítica, 1997.

Guerra Cabrera, C., Un mercader inglés en Tenerife en el siglo XVII. Biografía de Marmaduke Rawden. Tenerife, 1994.

Kepler, J. S., The Exchange of the Christendom. The International Entrepot at Dover, 1622-1641, Bristol, Leicester University Press, 1976.

Marcos Martín, Alberto, “España y Flandes (1618-1648): la financiación de la guerra", en José Alcalá-Zamora y E. Belenguer (coords.) Calderón de la Barca y la España del Barroco, Madrid, CEPC, 2001, (2): 15-39.

Marcos Martín, Alberto, "Movilidad social ascendente y movilidad social descendente en la Castilla moderna”, en Inés Gómez González y Miguel Luis LópezGuadalupe (eds.) La movilidad social en la España del Antiguo Régimen, Granada, 2007; 19-47.

Martínez, J. y Gauci, P., Mercaderes ingleses en Alicante en el siglo XVII, Universidad de Alicante, 2008.

Ruiz Martín, Felipe, Las finanzas de la monarquía hispánica en tiempos de Felipe IV (1621-1665). Madrid, Academia de la Historia, 1990.

Sanz Ayán, Carmen, Estado, monarquía y finanzas. Estudios de historia financiera en tiempos de los Austrias, Madrid, CEPC, 2004.

Sanz Ayán, Carmen, "Presencia y fortuna de los hombres de negocios genoveses durante la crisis hispana de 1640”, Hispania, 219, LXV/1 (Madrid, 2005): 91-114.

Sanz Ayán, Carmen, "Domésticos extranjerizados y extranjeros asimilados: linajes financieros de una monarquía en crisis”, en David González Cruz (ed.) Extranjeros y enemigos en Iberoamérica: la visión del otro, Madrid, 2010; 17-34.

Steckley, G. (ed.) The Letters of John Paige, London Merchant, 1648-1658, London Record Society, 1984.

Supple, B. E., Commercial Crisis and Change in England, 1600-1642. Cambridge, Cambridge University Press, 1959.

Taylor, Harland, "Trade, Neutrality and the English Road, 1630-1648», The Economic History Review, XXV/II (Londres, 1972): 236-260.

Recibido: 02-09-2011

Aceptado: 22-05-2012 